\title{
EDITORIAL
}

\section{Are There Really Important Relations Between Science and History?}

\author{
IAN WINCHESTER \\ University of Calgary
}

For those of us who encourage a close relationship between history, philosophy, and the teaching of natural science, it is sometimes good to reflect on why we do so. This special issue of Interchange is another in a long series of special issues in which history and natural science in a pedagogical context are brought together. But here, I want to reflect on just what, if any, the important relations between science and history may be.

There are numerous profound scientists who would deny the importance of the history of science as either a tool for the successful engagement in scientific research, or even for its pedagogy. For example, Lord Rutherford famously remarked that "science is either physics or stamp collecting," the implication being that all merely classificatory activities in science are not yet science. And of course the emphasis on stamp collecting, as in much of science before it is seen as law-like, is mere classification. Perhaps another would be Richard Feynman, possibly the most effective teacher of physics of his generation while he was at Cal Tech. His lectures on physics for early undergraduates at that institution, which is still going strong as an introductory text, does contain some historical material, but largely his work consists of an attempt to rethink the principles of his discipline from the vantage point of contemporary thought, without much concern as to how thought got where it presently is.

In his later Theory of Fundamental Processes (1961), Feynman tries to offer a course on quantum mechanics, beginning not with the developments of the $20^{\text {th }}$ century, say with puzzles surrounding black body radiation or the photoelectric effect, but rather jumps straight into the laws of quantum mechanics and the unusual thought necessary. The thinking that it involves is radically new, and compared to Newtonian thought, essentially unintuitive. Not surprisingly, he introduces socalled "Feynman Diagrams" very early on, and he illustrates how to calculate quantum phenomena beginning with them as illustrative of 
quantum processes. This, on first glance, appears to be an essentially history-free approach, or so he believes.

If we are to argue against this apparently history-free approach to the teaching of physics, it seems to me that we need some pretty fundamental grounds for doing so and I think there are such grounds. The first, and perhaps most important of these, is that both history and natural science, when they engage in their study of the world, begin with recorded facts - facts that are the result of human observation and recording. In neither historical work, as such, nor in the activities relating to observations in the natural sciences, need such observations be systematic though of course practitioners of both activities may engage in systematic observations.

One thinker concerned with both natural science and history, R.G. Collingwood, has suggested that since the facts of natural science as collected by scientific observers, are identical to the kinds of facts collected by historians for purposes of their work, that in fact natural science as a discipline or collection of disciplines actually presupposes the discipline of history before it can get off the ground. Of course, if true, this is a tacit presupposing, as most scientists certainly do not think they are historians when they collect their facts and later reflect on them or circulate them to other natural scientists for consideration. But what they circulate are data collected and ordered by them relating to a particular problem or task of observations relating to a question or problem in the context of contemporary natural science. And such data are identical to the kinds of data on which historians normally reflect. Indeed, both historians and scientists, when they bring their disparate data together, engage in what might be referred to as "record linkage processes" (see, for example, my "The Linkage of Historical Records by Man and Computers: Techniques and Problems" - 1970).

Of course there is one very important difference with respect to the uses that an historian, as such, puts her or his data compared to the uses to which natural scientists normally put their data. For the historian is characteristically interested in the individual event, usually a human event, as such: for example, Rutherford's discovery of the nucleus. But the scientist, say Rutherford, is interested in the generalizations, the law-like generalizations, which such data support with respect to the nucleus of an atom. For the historian, telling the history of science, both the facts relating to Rutherford's actions and thoughts are relevant, whereas to Rutherford and his colleagues interested in the nucleus, only the data surrounding Rutherford's measurements, as to scattering experiments, are important, not 
Rutherford's thinking processes. Of course, in the training of a scientist of the next generation the thought processes are crucial as a scientist-intraining will also have to learn to think in the kinds of ways that a firstrate scientist thinks about the problems with which they are engaged, including the thinking that leads to one realizing that there is a problem.

It would appear that Feynman did not realize that he was actually presenting a form of history of his own thought as a physicist in writing his lectures on physics or his book on fundamental processes. So I conclude that there is no particular reason why any natural scientist should be antagonistic to the history of their discipline. Indeed, not only are they presupposing it all the time, they are engaging in it explicitly when they teach their students how to go on in their scientific discipline.

Ian Winchester

Editor 